\title{
Adipose-derived mesenchymal stem/stromal cells: from the lab bench to the basic concepts for clinical translation
}

\author{
Yesica Romina FRONTINI-LÓPEZ ${ }^{1}$; Aldana Daniela GOJANOVICH ${ }^{1}$; Diego MASONE ${ }^{1,2}$; Diego Martín BUSTOS ${ }^{1,3}$; Marina UHART ${ }^{1}$ \\ ${ }^{1}$ Laboratorio de Integración de Señales Celulares. IHEM-CONICET, Universidad Nacional de Cuyo Mendoza, Argentina \\ ${ }^{2}$ Facultad de Ingeniería, Universidad Nacional de Cuyo, Mendoza, Argentina \\ ${ }^{3}$ Facultad de Ciencias Exactas y Naturales, Universidad Nacional de Cuyo, Mendoza, Argentina
}

Key words: hASC, Tissue regeneration, Cell therapy

\begin{abstract}
In the last years, much work has shown that the most effective repair system of the body is represented by stem cells, which are defined as undifferentiated precursors that own unlimited or prolonged self-renewal ability, which also have the potential to transform themselves into various cell types through differentiation.All tissues that form the body contain many different types of somatic cells, along with stem cells that are called 'mesenchymal stem (or stromal) cells' (MSC). In certain circumstances, some of these MSC migrate to injured tissues to replace dead cells or to undergo differentiation to repair it.The discovery of MSC has been an important step in regenerative medicine because of their high versatility. Moreover, the finding of a method to isolate MSC from adipose tissue, so called 'adipose-derived mesenchymal stem cells' (ASC), which share similar differentiation capabilities and isolation yield that is greater than other MSC, and less bioethical concerns compared to embryonic stem cells, have created self-praised publicity to procure almost any treatment with them. Here, we review the current techniques for isolation, culture and differentiation of human ASC (hASC), and describe them in detail. We also compile some advantages of the hASC over other stem cells, and provide some concepts that could help finding strategies to promote their therapeutic efficiency.
\end{abstract}

\section{Introduction}

Stem cells, defined as biological and functional living entities (or 'units') which are responsible for the organism development and the regeneration of organs and tissue systems, are under the spotlight for clinical translation. This is because they are easily expandable in vitro, since they self-renew, and because of their ability to differentiate to multiple cell lineages. Adult stem cells represent the most resourceful reservoir of cell progenitors, as they are found in potentially any body tissues. Mesenchymal stem (or stromal) cells (MSC) have been considered one of the most suitable sources for stem cell-based therapies because of their multipotential differentiation, by using these progenitors to replace or repair damaged musculoskeletal tissues (Murray et al., 2014). However, lately, it has been shown that MSC can differentiate not only into mesodermderived lineages but also to neuro-ectoderm lineages (Jaiswal et al., 1997; Mackay et al., 1998; Shiota et al., 2007; Gojanovich et al., 2018), broadening even more their action-span for clinical translation. To date, bone marrow supposes the most studied type of MSC since their identification in 1974 by Friedenstein et. al. (Friedenstein et al., 1974).

* Address correspondence to: Marina Uhart, muhart@mendoza-conicet.gob.ar

This paper belongs to the 60th Anniversary Collection of the Instituto de Histología y Embriología de Mendoza (IHEM)
Since the harvesting method for 'bone marrow mesenchymal stem cells' (BMSC) involves the iliac crest puncture, which can be accompanied by physical discomfort, even when the procedure is performed under local anesthesia, and because of possible side effects and morbidity, researchers have looked for alternative sources of MSC. In recent years, new MSC's tissue reservoirs have been recognized in Wharton's jelly (Wang et al., 2009), placenta (In't Anker et al., 2004), amniotic fluid (Tsai et al., 2004), menstrual blood (Borlongan et al., 2010), dental pulp (Pierdomenico et al., 2005), synovial membrane (De Bari et al., 2001) and adipose tissue (Zuk et al., 2001).

Like bone marrow, the adipose tissue derives from the mesenchyme, and consists of an upholding stroma that is in fact more easily accessible. The 'human adipose-derived mesenchymal stem cells' (hASC) are a population of cells with the advantage that they can be isolated from surgical wastes, because the adipose tissue is routinely discarded in abdominal dermolipectomy aesthetic surgery procedures. These hASC are derived from the 'stromal-vascular fraction' (SVF) of adipose tissue and were first described in 2001 by Zuk, who named them 'processed lipoaspirate' (PLA) (Zuk et al., 2001). As human bone marrow stem cells (hBMSC), hASC have the same multilineage differentiation capability, but adipose tissue is a more convenient available source, due to its subcutaneous location, less invasive collection 
techniques, minimal donor morbidity and higher isolation yield. All of these make hASC the most advantageous reservoir of hMSC and therefore it is being considered as highly promising in up-to-date regenerative medicine.

Along with hASC, the SVF includes other cell types that can be separated from them by adherent culture, since nonadherent cells are eliminated through washing and passaging, and non-proliferative cells are overgrown by hASC (Bourin et al., 2013), which can be easily expanded in number and handled under standard-culture conditions. As stated by the International Society for Cellular Therapy (ISCT) and the International Federation for Adipose Therapeutics and Science (IFATS), the identification of hASC comprises three criteria: adherence to plastic, specific surface antigen expression and in vitro differentiation into osteoblasts, adipocytes and chondroblasts (Dominici et al., 2006), which are discussed below.

Newly ground-breaking works are aiming to discover hASC natural niche and functions, as well as the possibility to manipulate them for therapeutic purposes. For these studies to be carried on humans, fluid scientists-doctors interactions are essential, as doctors bridge between patients and scientists. The initial contact may start in a scientific or medical congress or workshop, or researchers may contact physicians specifically to ask for tissue donations. Then, the protocol, project and informed consent are revised and approved by a competent bioethical committee. Once a surgery is scheduled, the doctor informs the patient about the possibility to donate the tissue, which otherwise would be discarded, without neither immediate personal reward nor any costs. The scientist has previously provided the clinical or hospital with information on how to collect and store the samples until pick up. After the samples arrive to the laboratory, they are used in research projects, ideally multidisciplinary or experimental-computational hybrid projects, in which the interpretation of the experimental data is used to feedback in silico analysis, that in turn generates new questions to be answered experimentally (Fig. 1).

We reviewed the aspects of hASC isolation, characterization, differentiation and some advantages regarding their use over other stem cells. Besides that, we introduce some notions and treatment ideas for hASC's successful clinical applications. This work attempts to bring to physicians concepts that are born from the basic science, trying to merge the knowledge of different disciplines, from molecular-cellular-computational biology to material engineering and modern medicine.

\section{hASC isolation}

Many hASC isolation protocols have been published during the last 15 years. Most of them consist of an enzymatic digestion of the adipose tissue to release the cells that form the SVF (Zuk et al., 2001). The later consists of an heterogeneous cell pellet including the hASC of interest plus circulating blood cells, fibroblasts, pericytes, endothelial and immune cells, and pre-adipocytes, among others (Lee et al., 2013; Nguyen et al., 2016). Recently, we published a protocol for hASC isolation, characterization and differentiation, with a detailed step by step description for these processes (Gojanovich et al., 2018). As all cell culture techniques, hASC isolation must be performed aseptically, in a biological safety cabinet. Briefly, we use about $100 \mathrm{~g}$ of freshly harvested subcutaneous adipose tissue obtained from abdomen dermolipectomy surgery of healthy patients, who has signed an informed consent to voluntarily donate the material. Once in the laboratory, the latter is chopped with surgical blades, we made several washes with phosphatebuffered saline (PBS) and centrifuged it to discard mainly the red blood cells, and then we incubate the tissue with an enzyme preparation. After digesting the tissue, we filter it through a $3 \mathrm{~mm}$ pore wire mesh to separate the connective tissue. The recovered liquid is centrifuged in order to obtain the SVF. During this process three liquid phases are obtained: (1) an upper yellow lipidic phase, product of the adipocytes rupture during processing; (2) a whitish intermediate phase containing mature adipocytes; and (3) an aqueous lower phase comprising culture medium and a cellular pellet corresponding to the SVF. Carefully, the lower liquid phase and cellular pellet is recovered and centrifuged. Then, the cellular pellet (or SVF) is resuspended in DMEM with $10 \%$ FBS, seeded in a $10 \mathrm{~cm}$ diameter tissue culture plate and incubated at $37^{\circ} \mathrm{C}$ and $5 \% \mathrm{CO}_{2}$. The following day, the plated cells are washed with PBS buffer and the medium is changed to wash away the remaining non-adherent cells. Cells are maintained in culture until reaching $90 \%$ confluence when they are divided for expansion (Gojanovich et al., 2018).

\section{hASC characterization}

Because there is no single marker to characterize the hASC population, it is necessary to perform a multicolor phenotyping analysis with a combination of fluorochromelabeled antibodies to specific surface antigens by flow cytometry, to evaluate the composition of the isolated population. Since there is no common protocol for isolating and cultivating MSC among laboratories, the ISCT and IFATS issued some criteria for identifying unique populations of these cells. According to this, ASC are characterized by the expression $(>80 \%)$ of CD13, CD29, CD44, CD73, CD90 and CD105 surface antigens, and must lack expression $(<2 \%)$ of CD31, CD45 and CD235a, as primary negative markers; while other low or negative markers include CD3, CD11b, CD49f, CD106 and PODXL (Bourin et al., 2013). However, according to Dominici et al. (2006), who established the first ISCT consensus, the phenotype characterization of multipotent MSC must include at a minimum the cell surface co-expression of the antigens CD105, CD73, and CD90 (positives) and the absence of hematopoietic and endothelial lineage markers CD45, CD34, CD14 or CD11b, CD79a or CD19, and HLA-DR (negatives) (Dominici et al., 2006). Since the hASC isolated in our laboratory are a subtype of hMSC and the characterization kit is intended for use on hMSC, all the surface markers analyzed allow us to perfectly identify our cell population.

Immunophenotyping analysis in our laboratory is achieved by labeling the cells with the BD Stemflow ${ }^{\mathrm{TM}} \mathrm{hMSC}$ Analysis Kit (Becton, Dickinson -BD-Biosciences, San Jose, CA, USA), which makes possible the characterization of MSC based on the Mesenchymal and Tissue Stem Cell Committee of the ISCT (Dominici et al., 2006). The hASC populations 
that we routinely obtain are highly enriched in hASC $(\geq 98 \%)$ and contain small amounts of other cells (less than $2 \%$ ) (Gojanovich et al., 2018).
Our characterization is comprehensive enough to accomplish the consensus of IFATS and ISCT, establishing that an ASC phenotyping should include at least two negative and two positive markers in the same analysis (Bourin et al., 2013).

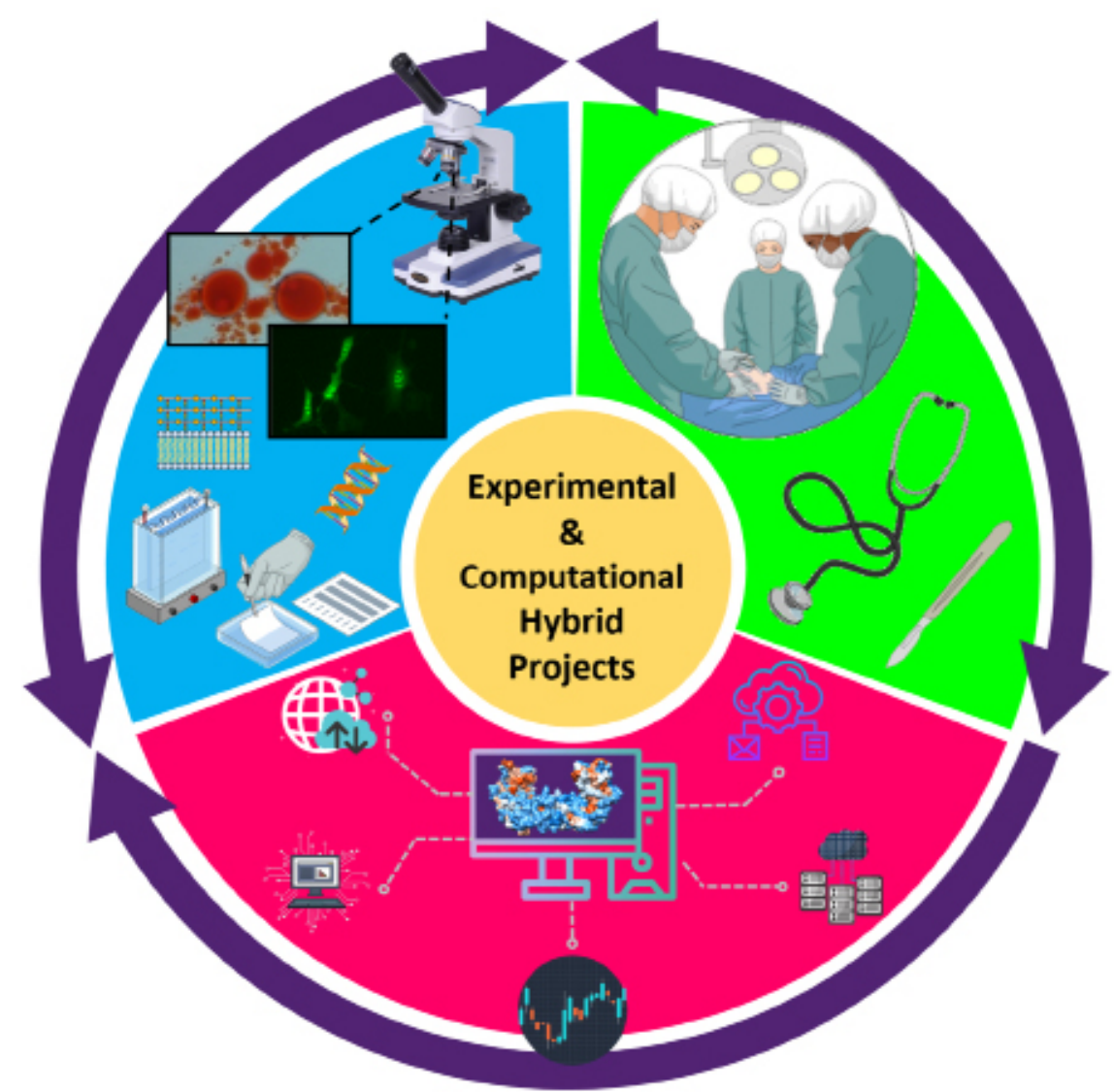

FIGURE 1. Diagram representing scientific research-clinics positive feedback. Clinical problems guide the construction of experimental and computational hybrid projects. Computational biology is used to predict experimental outcomes, optimize experiments planing and use of resources. Experimental biology (both in vitro and in vivo) will then generate new questions that feedback in silico studies, and will also generate innovations for clinical applications.

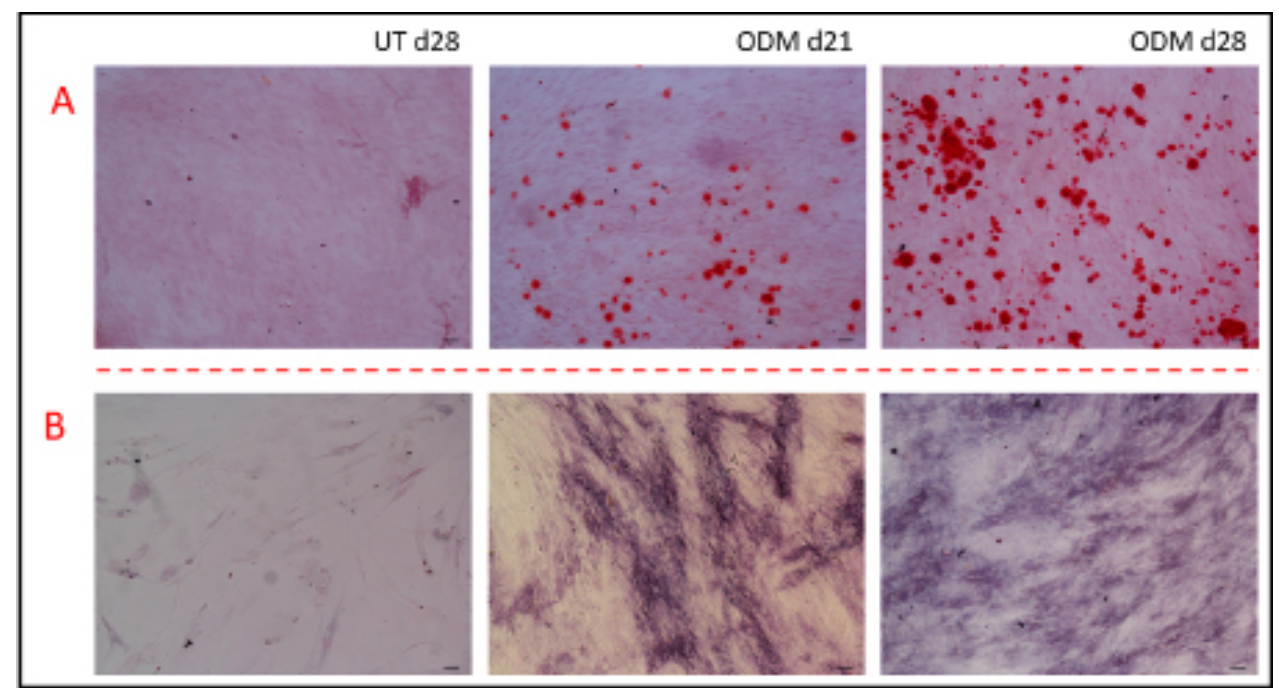

FIGURE 2. Osteogenic differentiation of adipose-derived mesenchymal stem/stromal cells. Untreated (UT) cells were maintained in Dulbeco's Modified Eagle Medium (DMEM) supplemented with 10\% fetal bovine serum (FBS), and osteogenic differentiation medium (ODM), containing DMEM+10\% FBS, plus $10 \mathrm{mM} \beta$-glycerophosphate ( $\beta$-GP), $100 \mathrm{nM}$ dexamethasone (DEX) and $50 \mu \mathrm{g} / \mathrm{mL} 2$-phospho-L-ascorbic acid (AA2P) at days 21 (d21) and 28 (d28) after induction. (A) Alizarin Red Staining of the hydroxyapatite mineralization nodules and (B) Alkaline phosphatase staining as an osteogenic biomarker protein (Scale bars: $50 \mu \mathrm{m}$ ). 


\section{hASC differentiation}

Several groups have demonstrated that hASC can differentiate into mature adipocyte cells through induction with a drug cocktail, which varies between protocols, but usually contains dexamethasone, insulin, 3-isobutyl-1methylxanthine (IBMX) and indomethacin or thiazolidinedione (TZD) (Bunnell et al., 2008). Dexamethasone is a glucocorticoid receptor agonist, which sensitize the insulin signaling (Tomlinson et al., 2010); insulin is a well-known hormone that stimulates glucose uptake; IBMX is a phosphodiesterase inhibitor used to increase the cAMP levels (Bunnell et al., 2008); both indomethacin and TZD are PPAR $\gamma$ agonists-ligands (Tontonoz \& Spiegelman, 2008).

Since there is no consensus about the optimal adipocyte differentiation protocol, we first tested several cocktail formulations on the 3T3-L1 cell line, a well-established murine pre-adipocyte cell line widely used for studying adipogenesis (Gojanovich et al., 2016). The best drug combination included dexamethasone, insulin, IBMX and rosiglitazone (a highaffinity PPAR $\gamma$ ligand, member of the TZD family). Next, we adapted the NIH 3T3-L1 adipogenesis protocol described in Gojanovich et al., (2016) for hASC adipogenic differentiation by introducing cycles of induction and maintenance medium, as detailed in Gojanovich et al. (2018).

To evidence the lipid droplets accumulation, we routinely use Oil Red O (Biopack, Buenos Aires, Argentina), which specifically stains triglycerides and cholesteryl oleate (Ramírez-Zacarías et al., 1992; Masone et al., 2017; Gojanovich et al., 2018).

The osteogenic differentiation of hASC requires a specific treatment of confluent monolayer with dexamethasone, $\beta$-glycerophosphate and ascorbic acid during three to four weeks to change their characteristic fibroblastoid morphology to a multilayer culture of elongated cells, typical of this differentiation (Bunnell et al., 2008; Langenbach \& Handschel, 2013). Based on literature information, combined with our results, the optimal concentration for osteogenic differentiation drugs are $100 \mathrm{nM}$ dexamethasone, $50 \mu \mathrm{g} / \mathrm{mL}$ 2-phospho-L-ascorbic acid and $10 \mathrm{mM} \beta$-glycerophosphate (Langenbach \& Handschel, 2013), replacing the osteogenic medium every two or three days. Briefly, dexamethasone induces hASC osteoblast differentiation by activating WNT/ $\beta$-catenin signaling-dependent RUNX2 expression; ascorbic acid facilitates differentiation by promoting Type I collagen (COL1A) secretion; and $\beta$-glycerophosphate favors extracellular matrix (ECM) mineralization by serving as a local source of inorganic phosphate ions.

Detection of calcium deposition after induction of differentiation can be detected by Alizarin Red S staining (Biopack, Buenos Aires, Argentina), since the dye forms a complex with the $\mathrm{Ca}_{10}\left(\mathrm{PO}_{4}\right)_{6}(\mathrm{OH})_{2}$ of the ECM in a chelation process, visualized as red mineralizing nodules (Bunnell et al., 2008) (Fig. 2A). To determine the alkaline phosphatase (ALP) activity as an osteogenic protein biomarker, we perform ALP staining using BCIP ${ }^{\circledR}$ (5-bromo-4-chloro-3-indolyl phosphate, Calbiochem, San Diego, CA, USA) which is hydrolyzed by the enzyme forming an intermediate product, that is then oxidized by the NBT (nitro blue tetrazolium, BDH Chemicals Ltd., Poole England, UK), generating an insoluble violet precipitate (McGadey, 1970) (Fig. 2B).
To assess chondrogenic differentiation, the micromass culture technique (Denker et al., 1995) is usually employed. Normally, a concentrated cell suspension is seeded in a 24 well plate and allowed to attach at $37^{\circ} \mathrm{C}$ for 2 hours. Cell-to-cell interaction in high cell density micropellets is critical to achieve a propitious chondrogenic process (Vinatier et al., 2009). After that, the chondrogenic medium containing TGF- $\beta$, insulin, transferrin, sodium selenite, dexamethasone, proline, and ascorbic acid is gently added so that the cell nodules are not detached (Zuk et al., 2001). It is well documented that TGF- $\beta$ increases the proteoglycans and Type II collagen (COL2A) synthesis rates and also cell proliferation (Awad et al., 2003; Vinatier et al., 2009); insulin, transferrin and sodium selenite, commonly known as ITS supplement medium, serves to enhance nutrition transportation into the inner part of the cartilage, promotes chondrocyte dedifferentiation process, and also production of polysulfonate glycosaminoglycans (GAGs) and COL2A (Liu et al., 2014); dexamethasone increments the proline uptake and upregulates aggrecan, proteoglycans and COL2A biosynthesis via SOX-9 transcription factor expression (Awad et al., 2003); proline and ascorbic acid are necessary as substrate and co-factor, respectively, of the prolyllysyl hydroxylase, a key enzyme in collagen biosynthesis (Temu et al., 2010). Cultures must be maintained with the chondrogenic medium during one month, with medium changes every two or three days.

The presence of ECM proteins characteristic of hyaline articular cartilage, like proteoglycan, can be confirmed by Alcian Blue, Toluidine Blue O or Safranin O staining (Jubb \& Eggert, 1981). Those are basically cationic dyes that form complexes with the anionic glycoconjugates of the cartilage ECM, such as GAGs and proteoglycans. The intensity of the staining is proportional to the amount of glycoconjugates in the hyaline cartilage (Terry et al., 2000).

\section{Clinical applications}

Since the beginning of the $21^{\text {st }}$ century, when the ASC were discovered, they appeared as particularly useful in the field of regenerative medicine because of their many advantages compared to other types of stem cells (Zuk et al., 2001). First of all, ASC can be easily harvested with minimal donor morbidity through liposuction or dermolipectomy surgery. The harvest method implies a higher yield on ASC isolation, and their capability of differentiation is similar to other MSC (Feisst et al., 2015). Moreover, ASC are not as questioned as embryonic stem cells because they are derived from adult adipose tissue (Dai et al., 2016).

Probably related to these advantages, it is noteworthy the number of clinical trials being accomplished at the moment with ASC. If we look for "adipose-derived stem cells" on the US National Institutes of Health (NIH) website (http:// www.clinicaltrials.gov), we can find that there are 112 studies, among which 42 are currently open. The great potential of stem cells to treat several human diseases like cancer, Parkinson's disease, diabetes mellitus, Crohn's disease, heart failure, autism, burns, amyotrophic lateral sclerosis, spinal cord injury, erectile dysfunction, premature ovarian failure, osteoarthritis, autoimmune diseases, etc. is well-known. A huge commercial "stem cell based therapies" industry is 
being built based on this potential, and it is alarming the increased number of companies that conveniently sell stem cells treatments that have not been proved in clinical trials because of the lack of regulation (Martell et al., 2010) in many countries. Indeed, a "stem cell tourism" has emerged to travel to less regulated countries to get treatments that are not approved in the more regulated ones.

In Argentina, there is still no legislation regarding the clinical use of stem cells. Nevertheless, the Instituto Nacional Central Único Coordinador de Ablación e Implante (INCUCAI) has declared that "the only stem cell treatment that has demonstrated safety and scientific efficacy is transplantation of hematopoietic progenitor (stem) cells in cases of onco-hematological diseases and out of this treatment there is no clinical evidence or treatments established at national and international levels, who have demonstrated the effectiveness of using stem cells to cure other diseases".
Along with their isolation-related qualities, hASC are highly attractive in the medical field, since they do not present surface molecules of class II major histocompatibility complex (MHCII), which allows them to be transplanted across allogenic barriers without eliciting an immune response (Le Blanc et al., 2003; Tse et al., 2003; De Miguel et al., 2012; Huang et al., 2016). If the hASC are to be used in clinics, it is mandatory to replace all traditional culture reagents by defined xeno-free reagents or, alternatively, more recently developed techniques which avoid the use of FBS or other animal sera are to be used (Cimino et al., 2017).

Hereafter, we describe a series of hASC's potential clinical applications in different medical areas, including their pros and cons (Fig. 3).

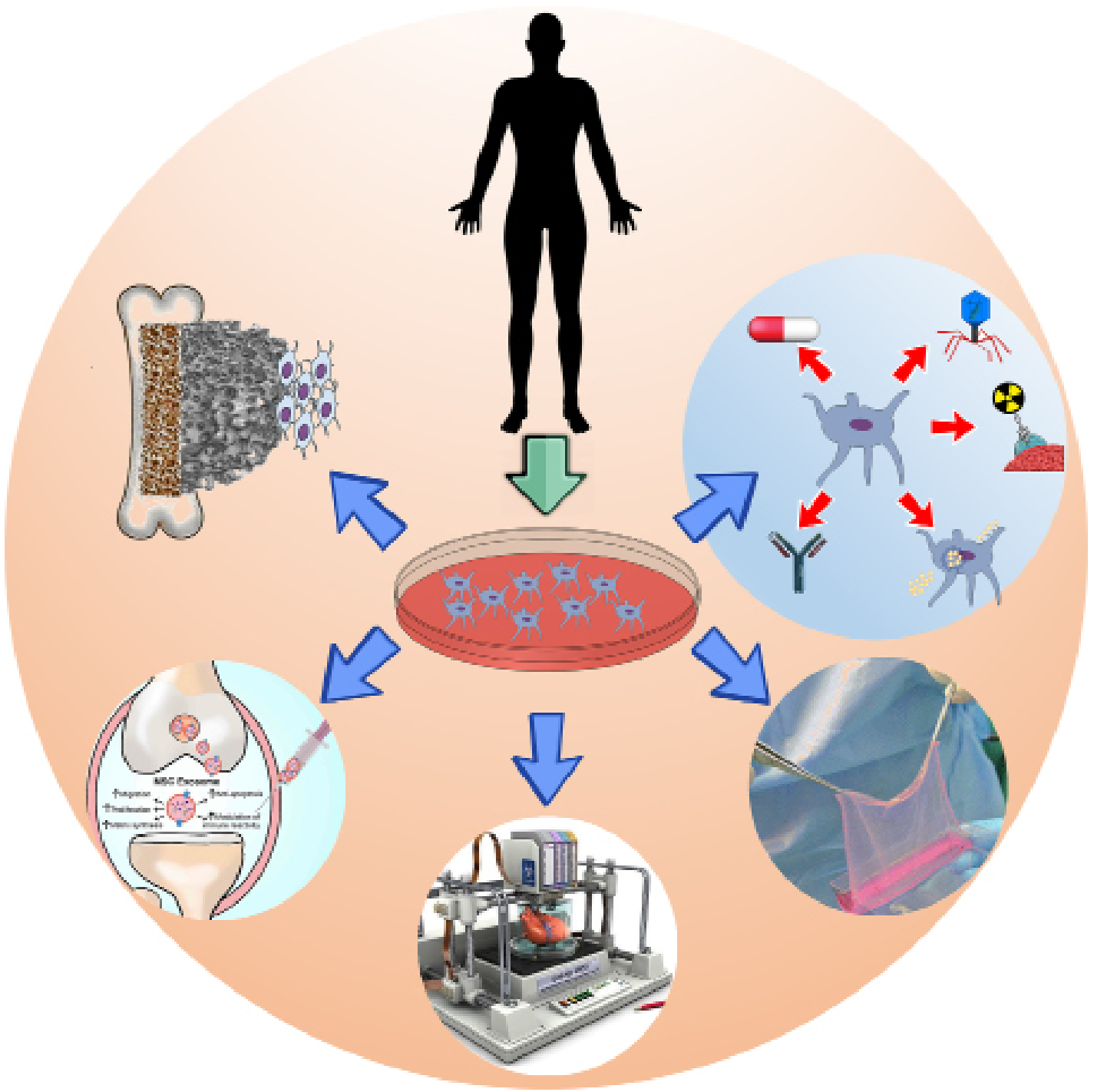

FIGURE 3. Human adipose-derived mesenchymal stem/stromal cells (hASC) potential clinical applications in different medical areas. As detailed in the article, hASC can be used to treat a wide variety of diseases. The fields with current greater advances are plastic and reconstructive surgery, bone and joint repair, $3 \mathrm{D}$ tissue printing and oncological therapies. 


\section{Oncology}

Several uses of hASC for oncolytic therapy have been proposed on the basis of their ability to home/migrate. But, what is it the homing/migration of the hASC and why does it happen? In 2009, Karp and Teo defined homing as "the arrest of MSC within the vasculature of a tissue followed by transmigration across the endothelium" (Karp \& Leng Teo, 2009). MSC express cytokines, chemokines and growth factors receptors on their surface, that allow them to migrate to the site of disease or injury by chemotactic gradients, which guide them to the damaged tissue (Cho et al., 2009). Although the homing/migration of the ASC has been tested in most cases, it seems that this capability is dependent on the injection method, and even when they manage to reach the damaged tissue, the amount grafted there is too low compared to the amount injected (De Becker and Riet, 2016). Controversially, Anjos-Afonso et al. (2004) transduced murine MSC with a lentiviral eGFP containing vector to track them within mice and found that mMSC migrate mostly to the lung, but also to other organs like liver, muscle and kidney, even in the absence of injury, and that they acquire the residing tissue morphology and antigen expression (Anjos-Afonso et al., 2004).

For cancer treatment, MSC have been proved as vehicles to deliver several anti-cancer therapies. Some examples include the expression of anti-cancer proteins (such as interleukins, pro-apoptotic proteins, etc.), the production of pro-drugs activating enzymes, the delivery of oncolytic viruses and nanoparticles containing chemo- or radiotherapies (Bhere and Shah, 2015). Even though these treatments seem promising, we must consider that they can be toxic even to the MSC themselves and also that the MSC can enhance the tumor severity because of their angiogenic capacity, or they may even generate a new tumor elsewhere (Fiala, 1968; Blanton et al., 2009). Recently, a novel strategy is being tested, which consists in MSC encapsulation (Murua et al., 2008). This approach requires not only the expertise of physicians and molecular biologists, but also bioengineers, thus a multidisciplinary team to deal with a bigger challenge.

\section{Drug screening and disease modeling}

Despite their source, the extent of stem cell's applications covers a wide scope. The advantages of their use in the field of drug screening rely on the promise of developing a more trustworthy, accelerated and profitable drug discovery process. Until 2015, less than $10 \%$ of the drugs that enter Phase I clinical trials, end up being approved successfully for disease treatment (Seruga et al., 2015). This information highlights the need to expand and improve the spectrum of new drug testing.

Most primary drug screening tests are carried out with cells grown on two-dimensional tissue culture plates or flasks. The aim of this method is to identify the largest number of hits, but it fails to mimic the niche complexity. That is when appears the need of using methods, which simulate better the in vivo situation.

Since the use of animal models in this research area tends to lead to drug failure and side-effects when translated to humans, due to interspecies differences (Miranda et al., 2018), it is necessary to address new approaches. In this matter, 3D assays could shorten the gap between primary screening and human trials, providing tools such as cellular aggregates or spheroids, the new developed constructs termed "organoids" and the most recently created organ-ona-chip platforms (Ranga et al., 2014; Miranda et al., 2018).

Cellular aggregates or spheroids for screening purposes are a powerful tool since there is no need to provide any adhesion matrices for cell adhesion. As an obstacle, they present heterogeneity and cellular disorganization, which leads to poor control of the size and differentiation of the cells within the spheroids (Ranga et al., 2014; Miranda et al., 2018).

The optimal assessment of drug effects and disease modeling should be carried out on models which best mimic the whole-organ composition, physiology and microenvironment, which implies a heterogeneous but uniformly distributed and organized cellular composition. For that matter, organoids, defined by Lancaster and Knoblich (2014) as "a collection of organ-specific cell types that develop from stem cells or organ progenitor cells to form an organ-like tissue exhibiting multiple cell types that self-organize to form a structure not unlike the organ in vivo" (Lancaster et al., 2014), are the new gold standard in drug screening and disease modeling. Their potential over spheroids lies in that they better simulate the migration, angiogenesis, and bioavailability of drugs when crossing biological barriers (Ranga et al., 2014). On the other hand, the current limitation of organoid culture is the scaleup production, since their formation is time-demanding (Miranda et al., 2018).

The need to fill the gap between in vitro testing and humans has led to the development of multi-organ platforms. Organs-on-a-chip provides a device which comes to improve the assessment of the interaction of the drugs and their metabolites with different parts of the body, recapitulating some other aspects of the human physiology like absorption, metabolic processing and toxicity. Nevertheless, since their accessibility is limited, its application is still restrained (Miranda et al., 2018).

\section{Bone regeneration}

The main challenge in the field of bone repair is to improve the osseointegration of implants in large bone injuries. Unlike small bone defects, where the human body has the innate ability to repair, bone healing in large bone injuries is delayed or absent. Before detailing some clinical strategies to reduce post-operative complications associated with graftversus-host disease in bone transplants, it is necessary to explain what we mean when we speak of osseointegration. This concept was first introduced by Professor Per-Ingvar Branemark (1969), who explained this process as "a direct structural and functional connection between ordered living bone and load-carrying endosseous implant at the light microscopic level" (Jayesh and Dhinakarsamy, 2015). In order to enhance osseointegration, it is of outstanding relevance to define three features that should have bone grafts: (1) osteogenesis: is the process by which new bone is synthesized, it requires cells with bone differentiation capacity; (2) osteoinduction: MSC are recruited to differentiate, this recruitment needs the regulation of growth factors and cytokines; (3) osteoconduction: is the three- 
dimensional growth of capillaries, perivascular tissue and stem cells from the receiving area of the host to the graft, generating a scaffold with the niche characteristics that favors the host-graft interface for regeneration (Zárate-Kalfópulos and Reyes-Sánchez, 2006).

Some cases in which MSC per se have been enough to repair bone defects (Lee et al., 2015; Fu et al., 2016; Zou et al., 2016) have been shown, but in general, the gold standard therapeutic strategy is to combine the components to induce bone growth and regeneration, taking into account the three above mentioned characteristics that should have bone grafts (Romagnoli and Brandi, 2014). Most suitable scaffolds must have pores that allow cell infiltration and extracellular matrix deposition; permit incorporation and control drugs, growth factors and bioactive components release; and should be comprised of resorbable materials so that they would be replaced by newly-formed bone over time (Romagnoli and Brandi, 2014).

There are basically two types of polymer scaffolds. Natural polymers are derived from biological sources, such as collagen, hyaluronic acid and alginate. These have the advantages of being biocompatible and bioactive, promoting cell attachment and growth. However, their liabilities are that they present a high risk of pathogen transmission, are difficult to engineer, and they exhibit batch-to-batch variability. On the other hand, synthetic polymers are far more malleable and have defined chemical formulation, so they can be easily sterilized. Nevertheless, despite their stability, synthetic materials can elicit undesirable inflammatory responses in vivo since they are not bioactive (Agarwal and García, 2015).

\section{Joint repair}

To understand the requirements of joint repairment it is necessary to recognize what are the symptoms of articular cartilage damage. Pathologies like osteoarthritis and rheumatoid arthritis begin to manifest by pain, swelling, limited motion and go on with cartilage degeneration (Nam et al., 2018). Progress of the illness severity is accompanied by changes that occur within the articular cartilage, especially regarding its composition.

There are mainly three types of cartilage: elastic cartilage, hyaline cartilage and fibrocartilage. Cartilage from joints is composed by hyaline cartilage, whose smoothness and flexibility are intermediate between elastic- and fibrocartilage (Nam et al., 2018). To add more complexity, the articular hyaline cartilage has different compositions of ECM according to its depth. Chondrocytes located at the surface of the articular cartilage secrete a protein named lubricin, which lubricates the joint. In the middle zone, chondrocytes mainly produce aggrecan and, in deeper regions, ECM is mostly composed by proteoglycans (Sakata et al., 2015; Nam et al., 2018).

Since chondrocytes are the only cell type and constitute $1-5 \%$ of the articular cartilage, and the joint, unlike most tissues, is avascular, it is almost impossible to repair an articular lesion regenerating hyaline cartilage. So when there is an imbalance between the catabolic and anabolic factors that lead to cartilage degradation, chondrocytes are replaced by fibroblast-like cells at the beginning and afterwards hyaline cartilage is replaced by fibrocartilage. These events prompt osteophyte formation, inflammation, rigidity and additional pain (Sakata et al., 2015; Nam et al., 2018).

Animal models are always the first choice in the attempt to imitate the endogenous condition, but because of size differences, joint thickness and healing potential, the results are difficult to extrapolate to humans (Sakata et al., 2015). Despite this drawback, MSC are more suitable since their therapeutic potential can be explained by two properties: (1) their capability of homing/migration, incorporation and further differentiation within the host, and (2) a battery of morphogens, chemokines and factors secreted by the MSC (Pak et al., 2018). This second characteristic is being currently harnessed to treat essentially knee and hip joints in osteoarthritis by intra-articular injection (Desando et al., 2013; Zhang et al., 2016; Cosenza et al., 2017; Seong et al., 2017).

Some other therapies applied for joint regeneration are microfractures, which consists in a procedure using special instruments that are inserted through small incisions in the underlying bone to induce the healing response, and 'autologous chondrocyte implantation' (ACI) in which chondrocytes are isolated from the low-weight-bearing part of a healthy joint and culture expanded in vitro. The liability of these methods relies in that microfractures can lead to fibrocartilage formation, and primary monolayer chondrocytes cultures tend to dedifferentiate them, which contributes to loss of its chondral characteristics, acquiring fibroblastoid morphology (Nam et al., 2018).

A new state-of-the-art technology to help cure joint injuries is the $3 \mathrm{D}$ bioprinting of cell droplets embedded on a scaffold. The deposition of the bioink, in turns, has to be controlled, cytocompatible, bioresorbable and satisfy the ECM features. Most suitable scaffolds for cartilage regeneration are composed of hydrogel, since gel consistency allows the mixing of the cells with growth factors and provide the lubrication characteristic, contributing to the cells commitment towards the chondrogenic phenotype (Roseti et al., 2018).

\section{Plastic and reconstructive surgery}

One of the most commonly performed procedures in this medical field is the transplantation of autologous fat graft, where lipoaspirated adipose tissue is reinjected without any previous process to separate different populations of cells. It is usually used in reconstructive and aesthetic surgery to fill defects and promote graft volume for tissue augmentation (Kaufman, 2007). This method has been improved by Matsumoto, who enriched the lipoinjection with SVF cells in order to promote a better engraftment of the implant (Matsumoto et al., 2006). The engraftment is thought to occur by the ASC's promoting revascularization properties during the acute phase of transplantation (Blanton et al., 2009). This procedure is advantageous because the adipose tissue from one reservoir of the body is removed and reimplanted in another site during a single surgery (Lin et al., 2008). On the other hand, this kind of reimplantation implies a serious risk, since it is likely to occur necrosis or resorption of the grafted fat (Coleman, 1995; Eto et al., 2012).

MSC are also applied in the treatment of chronic nonhealing cutaneous lesions such as fistulae in Crohn's disease, skin necrosis, tissue ischemia caused by previous irradiation, and burns. It has been suggested that hASC can improve skin healing because they have the ability to differentiate 
into endothelial progenitor cells, since they secrete vascular endothelial growth factor (VEGF), and have, indeed, a periendothelial location within the adipose tissue (Traktuev et al., 2008; Hsiao et al., 2012). This skin recovery characteristic is also attributed to the fact that hASC have immunomodulatory effects, which is given by their capacity to secrete cytokines, which confers them pro-coagulant and neo-angiogenic properties (Moll et al., 2012; Kapur and Katz, 2013). Another interesting feature about the ASC in wound healing is that they have shown to diminish excessive scar formation, improve color and scar pliability, associated with their antiinflammatory response (González et al., 2009; Yun et al., 2012).

Finally, when the injured areas are too large or relatively deep, the use of scaffolds immersed in a cell suspension (Kim and Jeong, 2014) is required. In Argentina, the first clinical trial for the treatment of large burn injury, approved by the INCUCAI is now on progress. This trial consists in the local and topical application of cadaveric BMSC through a fibrinbased polymer spray covering an acellular dermal biological matrix (Mansilla et al., 2012). Importantly, this trial is being performed with allogenic MSC instead of autologous ones.

An unsolved question regarding their use in skin regeneration is whether the application of living MSC is needed, since according to Wang et al., (2017) their usefulness seems to be mainly based on their secretory vesicles.

\section{Conclusions}

From 1912, when Alexis Carrel published the first drawing of a stem cell colony obtained in vitro from a chicken embryo (Carrel, 1912), to the finding in 2006 of the four factors to induce pluripotency in somatic cells by Shinya Yamanaka (Takahashi and Yamanaka, 2006), we have gone through a relatively slow period of learning on stem cells. But, in the last 12 years, along with advances in cell biology instrumentation and informatics, we have witnessed a great leap in our knowledge of stem cells potential.

Currently, there are almost five thousand clinical trials with stem cells from different sources. Of these, at least two thousand are being carried out with adult MSC, which highlights their utility. As we have already explained, ASC are a subtype of MSC, showing lots of advantages over other stem cells. Starting from the bioethical concerns regarding the use of embryonic stem cells, and continuing with ASC's greater yields, the identical capability of differentiation to other MSC and lack of MHCII in their surface, that allows allogenic transplantation without rejection, they suppose one of the most taking-into-account models to be applied in regenerative medicine.

ASC treatments have been proposed for a variety of diseases including musculoskeletal (osteoarthritis, rheumatoid arthritis, osteogenesis imperfecta), cardiac (heart failure, arrhythmia, myocardial infarction), neurological (Parkinson's disease, Amyotrophic Lateral Sclerosis, multiple sclerosis, Alzheimer's disease, schizophrenia), metabolic (Type I and II Diabetes), and hepatic diseases (liver cirrhosis). Several of the ongoing approaches in regenerative medicine, consider strikingly diverse parameters that influence the biological outcome within the niche of the target tissue. This adds complexity to the equation by introducing various professions (biologists, physicians and materials engineers), to combine their expertises in a single area (tissue engineering), for the creation of more effective treatments (Beldjilali-Labro et al., 2018).

One of greatest concerns regarding the ASC applications in medicine is that they may promote tumor growth, which has been shown in some studies where tumor cells proliferate more under ASC-conditioned medium or in co-culture of ASC with prostate cancer cells (Yu et al., 2008; Prantl et al., 2010). This fact is not surprising, since it has been proved that they secrete VEGF, which could stimulate metastases by generating new blood vessels within the tumor.

Although the use of ASC is quite promising, we must not disregard the need of adequate scientific groundings, for both their in vitro and in vivo handling, and stick to stringent laboratory good practices, like the use of non-xenogenic animal-derived products, to ensure optimal clinical results.

\section{Acknowledgments}

This work was supported by grants from ANPCyT (PICT-14 1659), CONICET (PIP-13CO01), SeCTyP-UNCuyo (J051) and the Roemmers Foundation. DM, MU and DMB are members of CONICET. YRFL and ADG, are fellows of the same institution.

\section{References}

Agarwal R García AJ (2015). Biomaterial strategies for engineering implants for enhanced osseointegration bone repair. Advanced Drug Delivery Reviews 94: 53-62.

Anjos-Afonso F, Siapati EK, Bonnet D (2004). In vivo contribution of murine mesenchymal stem cells into multiple cell-types under minimal damage conditions. Journal of Cell Science 117: 5655-5664.

Awad HA, Halvorsen YD, Gimble JM, GF (2003). Effects of transforming growth factor b1 dexamethasone on the growth chondrogenic differentiation of adipose-derived stromal cells. Tissue Engineering 9: 1301-1312.

De Bari C, Dell'Accio F, Tylzanowski P, Luyten FP (2001). Multipotent mesenchymal stem cells from adult human synovial membrane. Arthritis \& Rheumatism 44: 1928-1942.

De Becker A Riet IV (2016). Homing migration of mesenchymal stromal cells: How to improve the efficacy of cell therapy? World Journal of Stem Cells 8: 73-87.

Beldjilali-Labro M, Garcia AG, Farhat F, Bedoui F, Grosset JF, Dufresne M, Legallais C (2018). Biomaterials in tendon skeletal muscle tissue engineering: Current trends challenges. Materials 11: E1116.

Bhere D Shah K (2015). Stem Cell-Based Therapies for Cancer. Advances in Cancer Research 127: 159-189.

Blanton MW, Hadad I, Johnstone BH, Mund JA, Rogers PI, Eppley BL, March KL (2009). Adipose stromal cells platelet-rich plasma therapies synergistically increase revascularization during wound healing. Plastic and Reconstructive Surgery 123: 56S-64S.

Borlongan CV, Kaneko Y, Maki M, Yu SJ, Ali M, Allickson JG, Sanberg CD, Kuzmin-Nichols N, Sanberg PR (2010). Menstrual blood cells display stem cell-like phenotypic markers exert neuroprotection following transplantation in experimental stroke. Stem Cells Development 19: 439-452. 
Bourin P, Bunnell BA, Casteilla L, Dominici M, Katz AJ, March KL, Redl H, Rubin JP, Yoshimura K, Gimble JM (2013). Stromal cells from the adipose tissue-derived stromal vascular fraction culture expanded adipose tissue-derived stromal/stem cells: a joint statement of the International Federation for Adipose Therapeutics Science (IFATS) and the International Society for Cellular Therapy (ISCT). Cytotherapy 15: 641-648.

Bunnell BA, Estes BT, Guilak F, Gimble JM (2008). Differentiation of Adipose Stem Cells. In: Adipose Tissue Protocols, Second Edition (Kaiping Yang, ed.), pp. 155-171. Humana Press, New York City.

Carrel A (1912). On the permanent life of tissues outside of the organism. Journal of Experimental Medicine 15: 516-528.

Cho KS, Park HK, Park HY, Jung JS, Jeon SG, Kim YK, Roh HJ (2009). IFATS collection: Immunomodulatory effects of adipose tissue-derived stem cells in an allergic rhinitis mouse model. Stem cells 27: 259-265.

Cimino M, Gonçalves RM, Barrias CC, Martins MCL (2017). Xenofree strategies for safe human mesenchymal stem/stromal cell expansion: Supplements coatings. Stem Cells International 2017: 6597815 .

Coleman SR (1995). Long-term survival of fat transplants: Controlled demonstrations. Aesthetic Plastic Surgery 19: 421-425.

Cosenza S, Ruiz M, Toupet K, Jorgensen C, Noël D (2017). Mesenchymal stem cells derived exosomes microparticles protect cartilage bone from degradation in osteoarthritis. Scientific Reports 7: 1-12.

Dai R, Wang Z, Samanipour R, Koo KI, Kim K (2016). Adiposederived stem cells for tissue engineering regenerative medicine applications. Stem Cells International 2016: 6737345.

Denker AE, Nicoll SB, Tuan RS (1995). Formation of cartilagelike spheroids by micromass cultures of murine C3H10T1/2 cells upon treatment with transforming growth factor-beta 1 . Differentiation 59: 25-34.

Desando G, Cavallo C, Sartoni F, Martini L, Parrilli A, Veronesi F, Fini M, Giardino R, Facchini A, Grigolo B (2013). Intraarticular delivery of adipose derived stromal cells attenuates osteoarthritis progression in an experimental rabbit model Intra-articular delivery of adipose derived stromal cells attenuates osteoarthritis progression in an experimental rabbit model. Arthritis Research \& Therapy 15: R22.

Dominici M, Le Blanc K, Mueller I, Slaper-Cortenbach I, Marini F, Krause D, Deans R, Keating A, Prockop D, Horwitz E (2006). Minimal criteria for defining multipotent mesenchymal stromal cells. The International Society for Cellular Therapy position statement. Cytotherapy 8: 315-317.

Eto H, Kato H, Suga H, Aoi N, Doi K, Kuno S, Yoshimura K (2012). The fate of adipocytes after nonvascularized fat grafting: evidence of early death replacement of adipocytes. Plastic and Reconstructive Surgery 129: 1081-1092.

Feisst V, Meidinger S, Locke MB (2015). From bench to bedside : use of human adipose-derived stem cells. Stem Cells Cloning: Advances Applications 8: 149-162.

Fiala S (1968). The cancer cell as a stem cell unable to differentiate. A theory of carcinogenesis. Neoplasma 15: 607-622.

Friedenstein AJ, Deriglasova UF, Kulagina NN, Panasuk AF, Rudakowa SF, Luriá EA, Ruadkow IA (1974). Precursors for fibroblasts in different populations of hematopoietic cells as detected by the in vitro colony assay method. Experimental Hematology 2, 83-92.
Fu Q, Tang NN, Zhang Q, Liu Y, Peng JC, Fang N, Yu LM, Liu JW, Zhang T (2016). Preclinical study of cell therapy for osteonecrosis of the femoral head with allogenic peripheral blood-derived mesenchymal stem cells. Yonsei Medical Journal 57: 1006-1015.

Gojanovich AD, Bustos DM, Uhart M (2016). Differential expression accumulation of 14-3-3 paralogs in 3T3-L1 preadipocytes differentiated cells. Biochemistry Biophysics Reports 7: 106-112.

Gojanovich AD, Gimenez MC, Masone D, Rodriguez TM, Dewey RA, Delgui LR, Bustos DM, Uhart M (2018). Human adiposederived mesenchymal stem/stromal cells handling protocols. lipid droplets proteins double-staining. Frontiers in Cell Developmental Biology 6: 1-16.

González MA, Gonzalez-Rey E, Rico L, Büscher D, Delgado M (2009). Adipose-derived mesenchymal stem cells alleviate experimental colitis by inhibiting inflammatory autoimmune responses. Gastroenterology 136: 978-989.

Hsiao STF, Asgari A, Lokmic Z, Sinclair R, Dusting GJ, Lim SY, Dilley RJ (2012). Comparative Analysis of Paracrine Factor Expression in Human Adult Mesenchymal Stem Cells Derived from Bone Marrow, Adipose, Dermal Tissue. Stem Cells Development 21: 2189-2203.

Huang XP, Ludke A, Dhingra S, Guo J, Sun Z, Zhang L, Weisel RD, Li RK (2016). Class II transactivator knockdown limits major histocompatibility complex II expression, diminishes immune rejection, improves survival of allogeneic bone marrow stem cells in the infarcted heart. FASEB Journal 30: 3069-3082.

In't Anker PS, Scherjon SA, Kleijburg-van der Keur C, de GrootSwings GMJS, Claas FHJ, Fibbe WE, Kanhai HHH (2004). Isolation of Mesenchymal stem cells of fetal or maternal origin from human placenta. Stem Cells 22: 1338-1345.

Jaiswal N, Haynesworth SE, Caplan AI, Bruder SP (1997). Osteogenic differentiation of purified, culture-expanded human mesenchymal stem cells in vitro. Journal of Cellular Biochemistry 64: 295-312.

Jayesh RS, Dhinakarsamy V (2015). Osseointegration. Journal of Pharmacy \& Bioallied Sciences 7: S226-229.

Jubb RW, Eggert FM (1981). Staining of demineralized cartilage. II. Quantitation of articular cartilage proteoglycan after fixation rapid demineralization. Histochemistry 73: 391-396.

Kapur SK, Katz AJ (2013). Review of the adipose derived stem cell secretome. Biochimie 95: 2222-2228.

Karp JM, Leng Teo GS (2009). Mesenchymal stem cell homing: the devil is in the details. Cell Stem Cell 4: 206-216.

Kaufman MR, Miller TA, Huang C, Roostaeian J, Wasson KL, Ashley RK, Bradley JP (2007). Autologous Fat Transfer for Facial Recontouring: Is there science behind the art? Plastic and Reconstructive Surgery 119: 2287-2296.

Kim Y, Jeong J (2014). Clinical application of adipose stem cells in plastic surgery. Journal of Korean Medical Science 29: 462-467.

Lancaster MA, Knoblich JA (2014). Organogenesis in a dish: Modeling development disease using organoid technologies. Science 345: 1247125.

Langenbach F, Handschel J (2013). Effects of dexamethasone, ascorbic acid $\beta$-glycerophosphate on the osteogenic differentiation of stem cells in vitro. Stem Cell Research \& Therapy 4: 117.

Le Blanc K, Tammki L, Sundberg B, Haynesworth SE, Ringden O (2003). Mesenchymal stem cells inhibit stimulate mixed lymphocyte cultures mitogenic responses independently of 
the major histocompatibility complex. Scandinavian Journal of Immunology 57: 11-20.

Lee MJ, Wu Y, Fried SK (2013). Adipose tissue heterogeneity: implication of depot differences in adipose tissue for obesity complications. Molecular Aspects of Medicine 34: 1-11.

Lee SW, Jeon TJ, Biswal S (2015). Fracture healing effects of locallyadministered adipose tissue-derived cells. Yonsei Medical Journal 56: 1106-1113.

Lin K, Matsubara Y, Masuda Y, Togashi K, Ohno T, Tamura T, Toyoshima Y, Sugimachi K, Toyoda M, Marc H, Douglas A (2008). Characterization of adipose tissue-derived cells isolated with the Celution system. Cytotherapy 10: 417-426.

Liu X, Liu J, Kang N, Yan L, Wang Q, Fu X, Zhang Y, Xiao R, Cao $Y$ (2014). Role of insulin-transferrin-selenium in auricular chondrocyte proliferation engineered cartilage formation in Vitro. International Journal of Molecular Sciences 15: 1525-1537.

Mackay AM, Beck SC, Murphy JM, Barry FP, Chichester CO, Pittenger MF (1998). Chondrogenic differentiation of cultured human mesenchymal stem cells from marrow. Tissue Engineering 4: 415-428.

Mansilla E, Aquino VD, Roque G, Tau JM, Maceira A (2012). Time regeneration in burns treatment: Heading into the first worldwide clinical trial with cadaveric mesenchymal stem cells. Burns 38: 450-452.

Martell K, Trounson A, Baum E (2010). Stem cell therapies in clinical trials: Workshop on best practices the need for harmonization. Cell Stem Cell 7: 451-454.

Masone D, Gojanovich AD, Frontini-Lopez YR, Del Veliz S, Uhart M, Bustos DM (2017). Freely Available Tool (FAT). for automated quantification of lipid droplets in stained cells. Biocell 41: 55-58.

Matsumoto D, Sato K, Gonda K, Takaki Y, Shigeura T, Sato T, AibaKojima E, Iizuka F, Inoue K, Suga H, Yoshimura K (2006). Cellassisted lipotransfer: supportive use of human adipose-derived cells for soft tissue augmentation with lipoinjection. Tissue Engineering 12: 3375-3382.

McGadey J (1970). A tetrazolium method for non-specific alkaline phosphatase. Histochemie 23: 180-184.

De Miguel MP, Fuentes-Julian S, Blazquez-Martinez A, Pascual CY, Aller MA, Arias J, Arnalich-Montiel F, Fuentes-Julián S, Blázquez-Martínez A, Pascual CY, Aller MA, Arias J, Arnalich-Montiel F (2012). Immunosuppressive properties of mesenchymal stem cells: advances applications. Current Molecular Medicine 12: 574-591.

Miranda C, Fernandes TG, Diogo MM, Cabral JMS (2018). Towards multi-organoid systems for drug screening applications. Bioengineering 5: E49.

Moll G, Rasmusson-Duprez I, von Bahr L, Connolly-Andersen AM, Elgue G, Funke L, Hamad OA, Lönnies H, Magnusson PU, Sanchez J, Teramura Y, Nilsson-Ekdahl K, Ringdén O, Korsgren O, Nilsson B, Le Blanc K (2012). Are therapeutic human mesenchymal stromal cells compatible with human blood? Stem Cells 30: 1565-1574.

Murray IR, Corselli M, Petrigliano FA, Soo C, Péault B (2014). Recent insights into the identity of mesenchymal stem cells. The Bone \& Joint Journal 96: 291-298.

Murua A, Portero A, Orive G, Hernández RM, de Castro M, Pedraz JL (2008). Cell microencapsulation technology: Towards clinical application. Journal of Controlled Release 132: 76-83.

Nam Y, Rim YA, Lee J, Ju JH (2018). Current Therapeutic Strategies for Stem Cell-Based Cartilage Regeneration. Stem cells
International 25: 8490489.

Nguyen A, Guo J, Banyard DA, Fadavi D, Toranto JD, Wirth GA, Paydar KZ, Evans GRD, Widgerow AD (2016). Stromal vascular fraction: A regenerative reality? Part 1: Current concepts review of the literature. Journal of Plastic, Reconstructive \& Aesthetic Surgery 69: 170-179.

Pak J, Lee JH, Pak N, Pak Y, Park KS, Jeon JH, Jeong BC, Lee SH (2018). Cartilage regeneration in humans with adipose tissue-derived stem cells adipose stromal vascular fraction cells : updated status. International Journal of Molecular Sciences 19: E2146.

Pierdomenico L, Bonsi L, Calvitti M, Rondelli D, Arpinati M, Chirumbolo G, Becchetti E, Marchionni C, Alviano F, Fossati V, Staffolani N, Franchina M, Grossi A, Bagnara GP (2005). Multipotent mesenchymal stem cells with immunosuppressive activity can be easily isolated from dental pulp. Transplantation 80: $836-842$.

Prantl L, Muehlberg F, Navone NM, Song YH, Vykoukal J, Logothetis CJ, Alt EU, Alt E (2010). Adipose tissue derived stem cells promote prostate tumor growth. Prostate 70: 1709-1715.

Ramírez-Zacarías JL, Castro-Muñozledo F, Kuri-Harcuch W (1992). Quantitation of adipose conversion triglycerides by staining intracytoplasmic lipids with Oil red O. Histochemistry 97: 493-497.

Ranga A, Gjorevski N, Lutolf MP (2014). Drug discovery through stem cell-based organoid models. Advanced Drug Delivery Reviews 69-70: 19-28.

Romagnoli C, Brandi ML (2014). Adipose mesenchymal stem cells in the field of bone tissue engineering. World Journal of Stem Cells 6: 144-152.

Roseti L, Cavallo C, Desando G, Parisi V, Petretta M, Bartolotti I, Grigolo B (2018). Three-dimensional bioprinting of cartilage by the use of stem cells : a strategy to improve regeneration. Materials 11: E1749.

Sakata R, Iwakura T, Reddi AH (2015). Regeneration of articular cartilage surface: morphogens, cells, extracellular matrix scaffolds. Tissue Engineering Part B: Reviews 21: 461-473.

Seong W, Chai R, Hoi J, Hui P, Kiang S (2017). MSC exosome as a cell-free MSC therapy for cartilage regeneration : Implications for osteoarthritis treatment. Seminars in Cell and Developmental Biology 67: 56-64.

Seruga B, Ocana A, Amir E, Tannock IF (2015). Failures in Phase III: Causes consequences. Clinical Cancer Research 21: 4552-4560.

Shiota M, Heike T, Haruyama M, Baba S, Tsuchiya A, Fujino H, Kobayashi H, Kato T, Umeda K, Yoshimoto M, Nakahata T (2007). Isolation characterization of bone marrow-derived mesenchymal progenitor cells with myogenic neuronal properties. Experimental Cell Research 313: 1008-1023.

Takahashi K, Yamanaka S (2006). Induction of pluripotent stem cells from mouse embryonic adult fibroblast cultures by defined factors. Cell 126, 663-676.

Temu TM, Wu KY, Gruppuso PA, Phornphutkul C (2010). The mechanism of ascorbic acid-induced differentiation of ATDC5 chondrogenic cells. AJP: Endocrinology Metabolism 299: 325-335.

Terry DE, Chopra RK, Ovenden J, Anastassiades TP (2000). Differential Use of Alcian Blue Toluidine Blue Dyes for the Quantification Isolation of Anionic Glycoconjugates from Cell Cultures: application to proteoglycans a high-molecular-weight glycoprotein synthesized by articular chondrocytes. Analytical Biochemistry 285: 211-219.

Tomlinson JJ, Boudreau A, Wu D, Abdou Salem H, Carrigan A, Gagnon A, Mears AJ, Sorisky A, Atlas E, Haché RJG (2010). 
Insulin sensitization of human preadipocytes through glucocorticoid hormone induction of forkhead transcription factors. Molecular Endocrinology 24: 104-113.

Tontonoz P, Spiegelman BM (2008). Fat beyond: the diverse biology of PPARgamma. Annual Review of Biochemistry 77: 289-312.

Traktuev DO, Merfeld-Clauss S, Li J, Kolonin M, Arap W, Pasqualini R, Johnstone BH, March KL (2008). A population of multipotent CD34-positive adipose stromal cells share pericyte mesenchymal surface markers, reside in a periendothelial location, stabilize endothelial networks. Circulation Research 102: 77-85.

Tsai MS, Lee JL, Chang YJ, Hwang SM (2004). Isolation of human multipotent mesenchymal stem cells from second-trimester amniotic fluid using a novel two-stage culture protocol. Human Reproduction 19: 1450-1456.

Tse WT, Pendleton JD, Beyer WM, Egalka MC, Guinan EC (2003). Suppression of allogeneic T-cell proliferation by human marrow stromal cells: Implications in transplantation. Transplantation 75: 389-397.

Vinatier C, Bouffi C, Merceron C, Gordeladze J, Brondello JM, Jorgensen C, Weiss P, Guicheux J, Noël D (2009). Cartilage tissue engineering: towards a biomaterial-assisted mesenchymal stem cell therapy. Current Stem Cell Research \& Therapy 4: 318-329.

Wang L, Hu L, Zhou X, Xiong Z, Zhang C, Shehada HMA, Hu B, Song J, Chen L (2017). Exosomes secreted by human adipose mesenchymal stem cells promote scarless cutaneous repair by regulating extracellular matrix remodelling OPEN. Scientific Reports 7: 13321.
Wang SH, Lin SJ, Chen YH, Lin FY, Shih JC, Wu CC, Wu HL, Chen YL (2009). Late outgrowth endothelial cells derived from wharton jelly in human umbilical cord reduce neointimal formation after vascular injury. Arteriosclerosis, Thrombosis, Vascular Biology 29: 816-822.

Yu JM, Jun ES, Bae YC, Jung JS (2008). Mesenchymal stem cells derived from human adipose tissues favor tumor cell growth in vivo. Stem Cells Development 17: 463-474.

Yun IS, Jeon YR, Lee WJ, Lee JW, Rah DK, Tark KC, Lew DH (2012). Effect of human adipose derived stem cells on scar formation remodeling in a pig model: a pilot study. Dermatologic Surgery, 38: $1678-1688$.

Zárate-Kalfópulos B, Reyes-Sánchez A (2006). Injertos óseos en cirugía ortopédica. Cirugía y Cirujanos. 74: 217-222.

Zhang S, Chu WC, Lai RC, Lim SK, Hui JHP, Toh WS (2016). Exosomes derived from human embryonic mesenchymal stem cells promote osteochondral regeneration. Osteoarthritis Cartilage 24: 2135-2140.

Zou L, Chen Q, Quanbeck Z, Bechtold JE, Kaufman DS (2016). Angiogenic activity mediates bone repair from human pluripotent stem cell-derived osteogenic cells. Scientific Reports 6: 22868.

Zuk PA, Zhu MIN, Mizuno H, Benhaim P, Lorenz HP (2001). Multilineage Cells from Human Adipose Tissue : Implications for Cell-Based Therapies. Tissue Engineering 7: 211-228. 